\title{
3. The changing nature of government: network governance
}

\section{William D. Eggers}

Governing by network is at the heart of numerous major Australian Federal Government initiatives.

In the twentieth century, hierarchical government bureaucracy was the predominant organisational model used to deliver public services and fulfil public-policy goals. Public managers won acclaim by ordering those under them to accomplish highly routine - albeit professional - tasks with uniformity but without discretion. Today, increasingly complex societies force public officials to develop new governance models.

In many ways, twenty-first-century challenges and the methods of addressing them are more numerous and complex than ever. Problems have become both more global and more local as power disperses and boundaries (when they exist at all) become more fluid. One-size-fits-all solutions have given way to customised approaches as the complicated problems of diverse and mobile populations increasingly defy simplistic solutions.

The traditional, hierarchical government model simply does not meet the demands of this complex, rapidly changing age. Rigid bureaucratic systems with command-and-control procedures, narrow work restrictions and inward-looking cultures and operational models are particularly ill suited to addressing problems that often transcend organisational boundaries.

The hierarchical model of government is in decline, pushed by governments' appetites to solve ever more complicated problems and pulled by new tools that allow innovators to fashion creative responses. This push and pull is gradually producing a new government model, in which executives' core responsibilities no longer centre on managing people and programs but on organising resources - often belonging to others - to produce public value. We call this trend 'governing by network'.

Complex public-private, network-to-network collaboration models now operate, with varying degrees of success, in nearly every area of Australian government. As outsourcing, partnerships and network models multiply, scores of Australian public agencies have become de facto contract-management agencies.

In the private sector, customer-oriented corporations and corporations that are directly in contact with the public have changed their product and service-delivery systems in recent times. In the public sector, we are now finding 
that service delivery by government is also adapting to a new context by relying on various partnerships with others. In such circumstances, networking becomes a critical skill for public-sector managers.

Whether the challenge is responding to natural disasters such as the South-East Asian tsunami or protecting Australia's citizens and critical infrastructure from terrorism, there is a growing recognition that the traditional, hierarchical model of government is inadequate

\section{Governing by network: a new model of achieving results}

The fundamental issue facing many Australian government executives today, across the various levels of government, is how to conceptualise, configure and manage a network of public, private and non-profit providers in a way that generates increased value for citizens.

In the past year, I have spent time with dozens of senior Australian government officials and leaders from the private sector and Australia's fledgling non-profit community, talking about the future of government. We have met with chief executives from many of the largest federal agencies in Canberra, senior public servants in Victoria, New South Wales and Queensland, and numerous local government officials. The purpose of these meetings has been to discuss the ways in which modern governments are changing to meet today's challenges.

Governing by network cannot succeed without robust knowledge sharing. Cross-sectoral knowledge sharing can help develop new knowledge, flesh out solutions to daily problems, enhance learning across the network and build trust and aid in learning from one another's successes-and mistakes. These capabilities, in turn, can help government better integrate and align its own strategic objectives with those of its partners.

\section{A fundamentally different approach}

These discussions have convinced us that hierarchical government bureaucracy - the principal organisational model used for more than a century to deliver public services in Australia and most of the developed world-is beginning to give way to a fundamentally different approach.

Governing by network is at the heart of numerous major Australian Federal Government initiatives. The Department of Employment and Workplace Relations' welfare-to-work program relies mostly on a network of hundreds of private and non-profit organisations to move individuals from dependency to independence. Different commercial and contractual arrangements and relationships exist across the different sub-national jurisdictions and regional markets.

Meanwhile, the Australian Business Entry Point, a government business portal, partners with more than 160 individual businesses and associations to syndicate 
government information and transactions relevant to business. Partners such as Westpac, CPA Australia (the sixth-largest accounting body in the world) and NineMSN (Australia's top web site) are just a few of the active companies that use the Business Entry Point's reverse portal service to offer value-added resources to their customers.

At the state level, Gary Tweedlie, the chief executive of Victoria's WorkCover Authority - the state accident fund that insures about three million workers and oversees workplace safety - has used a networked model to dramatically improve the agency's performance. Performance-based contracts with four major insurers and two third-party claims administrators have helped to reduce the agency's liabilities by more than $\$ 1.5$ billion. On the safety side, workplace injuries have been cut through a bevy of partnerships with trade unions, businesses and professional associations.

\section{Challenges posed for governments by working through networks}

The movement from command government to networked governance is not just a recent phenomenon in Australia. It is a global development driven by various business and societal forces. It was led by the public's growing demand for personalised and integrated services, the plummeting costs of engagement and collaboration (thanks to the Internet and other new technologies), the enhanced level of outsourcing and the growing number of complex problems that demanded cross-governmental and cross-sectoral responses. Network governance has also enabled governments to extend their influence and responsibilities into areas of community need and value. These expectations and societal forces have in turn confronted governments with other difficult choices.

As local, state and federal governments and agencies in Australia continue the journey to more networked governance, it is important to recognise that while government by network offers vast benefits (including greater reach and specialisation), it also poses serious challenges and policy dilemmas. It is not always a 'win-win' or 'costless' transition.

One such dilemma surfaced prominently during the planning debates for Sydney's Cross-City Tunnel and its associated toll roads. The issue revolves around how governments should protect public values. Should public side roads or exit roads be closed, diverted or narrowed to force local traffic onto a toll road? Should governments use their authoritative powers to attempt to make public-private partnership (PPP) schemes profitable for the partners - and guarantee the planned volumes of users? Or, in another PPP example that we know of, what if the private partner in a major urban redevelopment project with by far the best financial offer nevertheless refuses to increase its share of minority and women subcontractors? Should the government accept this or 
intervene? Should contracts be let to such providers in the future? Network governance places traditional and new forms of accountabilities on elected governments.

\section{Safeguarding the public interest}

Sometimes the public purpose or public value line blurs or becomes distorted. This is one reason why public officials must be careful to protect important values at every stage of the process. In many collaborations that involve a great deal of necessary messiness, it means asking questions such as: what are the core values that governments must protect; how can public officials maintain the integrity of these values; what is the best and most appropriate role for the government in the delivery of desired services; and how will accountabilities and potential risks be managed? Answering these questions requires working through issues such as access to services, citizen costs, fairness and equity, financial accountability, sustainability and stability and quality of service.

\section{Networking also involves human-resource challenges for traditional governments}

Another daunting challenge for networked governance is dealing with the people issue. Managing in a networked environment requires a whole set of competencies and capabilities separate to and beyond those expected of hierarchical government. In addition to knowing about planning, budgeting, staffing and other traditional government duties, networked management requires becoming proficient in tasks such as collaboration, engagement skills, negotiating deals as well as working with and managing third-party service providers. These skills are not currently uppermost in government - and many of these skills defy or confound the traditional emphasis on due process and conventional control orientations. Such skills will also tend not to flourish in agencies in which a self-protective mentality reigns or in which a culture of turf ownership is prevalent. Networking means letting go to some extent in order to achieve better outcomes for citizens.

Today, government agencies need senior public officials who can see through restrictive government walls and defensive practices into the potentiality of relationships that might produce value. They need to develop agile managers with sophisticated skills in team building, project management and risk analysis.

They need frontline and middle-management employees who can collaborate with outside partners and quickly adapt to rapidly changing environments. They need staff prepared to take risks and to explore opportunities. Unfortunately, according to the Australian Public Service Commission, these kinds of skills are also the ones of which there is the most profound shortage in Australian government. They are also the skills governments typically find hardest to encourage. 
Employees today need much more mobility and opportunity to move from project to project without sacrificing career advancement. Highly restrictive human-resource and public-sector regulations need updating to enable employees to bring broad skills to their assigned projects, unrestricted by the narrow 'bands' or grades in which they are employed.

Lynelle Briggs, Australia's Public Service Commissioner, recently argued that government leaders must look for people with broader skill sets and more flexible deployment patterns. She argued that 'the future will be one of greater diversity in careers...more movement in and out, with more part-time and different working patterns'. The question is: is the sector prepared for this change and can it anticipate and deal with the consequences?

\section{A final summary}

Sometimes networked governance fails not because of how a particular venture is managed, but because of what was delegated to the private sector in the first place. All too often, precious little thought is given to what policy goals an agency is trying to accomplish and how they relate to what is contracted out. Instead, agency officials pick up their organisational chart, look for something they are not doing very well and then get the private sector to do it for them.

Before federal executives think about how they should do something, they need to figure out what they are trying to do in the first place. The government executive, hamstrung by precedent and reinforced by well-intentioned bureaucratic practices, often will find it difficult to step into the larger, more important and more exciting role of conceptualising new models and solutions.

I have argued that thriving in the networked age requires governments to change the way they think and operate. Governments in the future will not simply be bureaucratic providers of a narrow range of public goods. They will no longer merely occupy the space traditionally promulgated and occupied by governments to act as monopolist service owner and direct service provider. Instead, governments will act as aggregators of networks, managers or partnered arrangements and buyers of diverse services and new forms of value. In this transformation, they will need to refashion their systems, practices, structures and skill sets in a way that reflects the government's new roles in service delivery and working through network governance models.

It is important to understand that today's complex problems often require carefully integrated solutions. In certain instances, governments can act as their own 'general contractor', but that role requires the federal executive to think creatively across product lines and agencies, build an intergovernmental network before the procurement process starts and find internal management talent that can creatively configure the best possible solution. When the capacity to do this is absent, executives must recognise that the ability of the private sector to 
properly integrate the parties into a solution might, in fact, be the most important asset to be procured.

The day-to-day business of working in networks is infinitely more complex and more difficult than managing a traditional bureaucracy. It requires a whole different set of skills. In addition to knowing about planning, budgeting, staffing and other traditional government duties, networked management requires proficiency in a host of new tasks, such as business process re-engineering, negotiation, mediation and network design.

Unfortunately, such skills aren't exactly plentiful in the public sector, nor are they typically recognised or rewarded. The way to get ahead in government has been to be an adviser on policy issues or demonstrate a solid ability to manage government employees, not to show proficiency in negotiating deals and managing third-party service providers. As a result, some agencies don't even have effective contract-management capabilities, much less the capacity to handle the vastly more sophisticated requirements of network management.

Building such capacity requires not only far-reaching training and recruitment strategies, it requires a full-blown cultural transformation. What is required is nothing less than changing the definition of what it means to be a public employee.

Contracting and relationship skills can no longer be the province only of acquisition employees. People with these skills - skills that currently are not highly valued in government - need to be recruited, rewarded and promoted.

The reflexive opposition on the political left to all things outsourced, and the failure of those on the right to acknowledge that far too many contracting endeavours fail to measure up to expectations, are symptomatic of a stale debate that is still stuck in a 1980s ideological box. To succeed in an age of networked government, we need not only to update our approach to government, we need to update our thinking.

\section{References}

Eggers, William D. and Goldsmith, Stephen 2003, 'Networked government', Government Executive, June.

Eggers, William D. and Goldsmith, Stephen 2004a, 'Governing by network: CIOs and the new public sector', Public CIO Magazine, 10 November 2004, $<$ http://www.govtech.com/pcio/92107?id=\&story_pg=1>

Eggers, William D. and Goldsmith, Stephen 2004b, Governing by Network: The new shape of the public sector, Brookings Institution Press, Washington, DC. 